\title{
Leitura literária em voz alta, em grupo on-line, em tempos de pandemia
}

\author{
Daniela Favero Netto 1 \\ Adauto Locatelli Taufer ${ }^{2}$ \\ Luíza Amaral Rockenbach ${ }^{3}$ \\ Ewaldo Campos Martins ${ }^{4}$
}

\begin{abstract}
Resumo:
Este trabalho apresenta um relato de experiência de leitura em voz alta, em grupo, em tempos de pandemia. A proposta de leitura, direcionada à formação do leitor literário em idade escolar, foi realizada no segundo semestre de 2020, como uma das ações do projeto de extensão, oriundo do Colégio de Aplicação (UFRGS), intitulado Mediação de Leitura e Escrita (MESCLE). A obra selecionada para leitura em grupo foi Senhor das Moscas, de William Golding ([1954] 2014). O grupo se reunia uma vez por semana em plataforma on-line, totalizando 15 encontros entre setembro e dezembro do referido ano. Objetivou-se com essa proposta de mediação de leitura, via ação de extensão, proporcionar a leitura de um texto literário em grupo com vistas ao compartilhamento de impressões de leitura, dando vez e voz aos jovens leitores em formação. Os pressupostos teóricos de Bajour (2012), de Cosson (2020), de Petit $(2009,2013)$ e de Rouxel (2013) serviram de base para alicerçar as atividades de mediação de leitura planejadas para a ação de extensão, apontando para escolhas metodológicas, que, se bem observadas, recuperam aspectos presentes na natureza da recepção do texto literário, o que, por si só, já é uma sugestão de abordagem dessa modalidade de texto.
\end{abstract}

\section{Palavras-chave:}

Projeto de extensão. Leitura em voz alta. Formação do leitor.

\footnotetext{
1 Doutora em Letras - Estudos da Linguagem, na Linha de Pesquisa Linguística Aplicada, pela Universidade Federal do Rio Grande do Sul (2017) e docente do Colégio de Aplicação. E-mail: d.faveronetto@gmail.com ORCID iD: http://orcid.org/00000002-1367-1263

2 Doutor em Letras - Estudos de Literaturas Brasileira, Luso-Africanas e Portuguesa, pela Universidade Federal do Rio Grande do Sul (2011), pós-doutor em Teoria da Literatura e Escrita Criativa, pela Pontifícia Universidade Católica do Rio Grande do Sul (2020) e docente do Colégio de Aplicação. E-mail: adautotaufer@gmail.com ORCID iD: http://orcid.org/0000-0001-5855-4792 3 Graduanda em Letras - Licenciatura, com ênfase em Português/Inglês, pela Universidade Federal do Rio Grande do Sul e bolsista de Iniciação Científica (FAPERGS/UFRGS). E-mail: luizarockenbach11@gmail.com ORCID iD: http://orcid.org/0000-0003-4716-4136

4 Graduando em Letras - Licenciatura, com ênfase em Português/Espanhol, pela Universidade Federal do Rio Grande do Sul e bolsista de Iniciação Científica (FAPERGS/UFRGS). E-mail: ewaldomartins@gmail.com

ORCID iD: http://orcid.org/0000-0001-7993-6431
} 


\title{
Literary reading aloud group during pandemic times
}

\begin{abstract}
:
This paper shows an experience report about a literary reading aloud group, during pandemic times. The reading proposal, which was directed to reader's formation in High school age, was carried out in the second semester of 2020 as one of the activities of the extension project created at Colégio de Aplicação (UFRGS) and called Mediação de Leitura e Escrita (MESCLE). The book selected for the group reading was Senhor das Moscas, by William Golding ([1954] 2014). The group meetings occurred once a week in on-line platform: in total, there were 15 meetings between September and December in 2020. The point of these reading mediation was to provide the reading of a literary text in a group, in order to gather reading impressions and different sharings, mostly from the young readers in formation. The theoretical assumptions from Bajour (2012), Cosson (2020), Petit $(2009,2013)$ and Rouxel (2013) were used to reinforce the mediation reading' activities planned for the extension project pointing to methodological choices, that aim to recover aspects seen in the nature of literary reception, suggesting this kind of approach.
\end{abstract}

\section{Keywords:}

Extension project. Reading aloud. Reader's formation.

\section{Lectura literaria en voz alta, en grupo en línea, en tiempos de pandemia}

\section{Resumen:}

Este trabajo presenta un relato de experiencia de lectura en voz alta, en grupo, en tiempos de pandemia. La propuesta de lectura, dirigida a la formación del lector literario en edad escolar, fue realizada en el segundo semestre de 2020, como una de las acciones del proyecto de extensión, oriundo del Colégio de Aplicação (UFRGS), denominado Mediação de Leitura e Escrita (MESCLE). La obra seleccionada para la lectura en grupo fue Senhor das Moscas, de Willian Golding ([1954] 2014). El grupo se reunió una vez por semana en plataforma en línea, totalizando 15 encuentros entre septiembre y diciembre de 2020 . El objetivo de esa propuesta de mediación de lectura, por medio de la acción de extensión, fue proporcionar la lectura de un texto literario en grupo con el objetivo de compartir las impresiones de lectura, donando vez y voz a los jóvenes lectores en formación. Los presupuestos teóricos de Bajour (2012), de Cosson (2020), de Petit $(2009,2013)$ y de Rouxel $(2013)$ han servido de base para cimentar las actividades de mediación de lectura planeadas para la acción de extensión, apuntando para elecciones metodológicas, que, se bien observadas, recuperan aspectos presentes en la naturaleza de la recepción del texto literario, o que, por sí solo, ya es una sugerencia de abordaje de esa modalidad de texto.

Palabras clave:

Proyecto de extensión. Lectura en voz alta. Formación del lector.

\section{Uma experiência em tempos de pandemia: leitura literária em voz alta, em grupo}

Este relato discorre sobre uma proposta realizada no âmbito do projeto de extensão MESCLE - Mediação de Escrita e Leitura -, coordenado por dois professores pertencentes ao quadro de servidores públicos efetivos do corpo docente do Colégio de Aplicação da UFRGS. A proposta, direcionada à formação do leitor literário em idade escolar, trata-se de uma ação de 
extensão que, através da criação de um grupo virtual, viabilizou a leitura em voz alta da obra Senhor das Moscas, do autor William Golding, publicada originalmente em 1954 e traduzida para 35 idiomas.

A construção da narrativa em Senhor das Moscas coloca em evidência as relações humanas, em um microcosmo social constituído por crianças, levando o leitor a inevitavelmente estabelecer associações com sua realidade mais próxima, em uma alegoria que coloca em xeque as noções de "bem" e "mal" da condição humana. Esse microcosmo possibilita, ainda, refletir sobre as relações de poder e de limite entre ordem e violência, as quais ficam ainda mais latentes quando crises, das mais diversas naturezas, se instauram em determinada sociedade. Um dos tópicos do livro trata, indiretamente, da ordem versus caos, representando metaforicamente a linha tênue entre um sistema democrático e a tirania de inúmeros cenários políticos espalhados pelo mundo.

As propostas de extensão, no âmbito da Universidade Federal do Rio Grande do Sul, "na área de cultura, de educação e de inclusão, constituem-se em ferramentas valiosas para criar, na própria sociedade, ambientes de aprendizagem e grupos multidisciplinares que a nova realidade socioeducativa demanda." ${ }^{5}$ Em diálogo com o que pretende a Pró-Reitoria de Extensão da UFRGS (PROREXT), a ação de extensão de que este texto trata buscou atender uma necessidade que ficou inviabilizada pela pandemia da COVID-19, que resultou, entre outras medidas sanitárias, no fechamento das escolas, que passaram a atender estudantes em ambiente virtual. A ação Leitura literária em voz alta: Senhor das Moscas - grupo de leitura voltou-se, assim, ao compromisso com o incentivo à leitura e à mediação de leitura entre jovens leitores e a referida obra, o que não poderia ser desenvolvido presencialmente no momento em que foi proposta a ação.

A definição de uma obra específica para a leitura, antes de convidar o público a participar do grupo, decorreu do entendimento da importância de eleger um livro com temas atuais, propiciando a construção de relações mais complexas; portanto, uma leitura desafiadora. Nesse sentido, a prática de leitura com a presença de mediadores foi fundamental para a progressão e para o estímulo de discussões mais apuradas. Por fim, entendemos que a divulgação do grupo, sem convidar à leitura de uma obra específica, poderia não ser atrativa. Se a divulgação informasse que o grupo elegeria em conjunto a obra a ser lida, ela poderia não atrair os leitores menos experientes para a primeira experiência de leitura em voz alta em grupo, porque poderiam se perguntar "vou participar de um grupo de leitura para ler exatamente o quê??".

O convite à participação no grupo realizou-se por meio de um folder postado nas redes sociais (Instagram e Facebook) dos coordenadores do projeto de extensão e de seus bolsistas de pesquisa, o qual foi repostado pelos primeiros interessados em aderir à proposta, constituindo-se em um grupo com um total de 20 participantes: estudantes dos anos finais do ensino fundamental e do ensino médio, de escolas de Porto Alegre e da Região Metropolitana, das redes pública e privada. 
Figura 1 - Folder de divulgação do grupo de leitura em voz alta

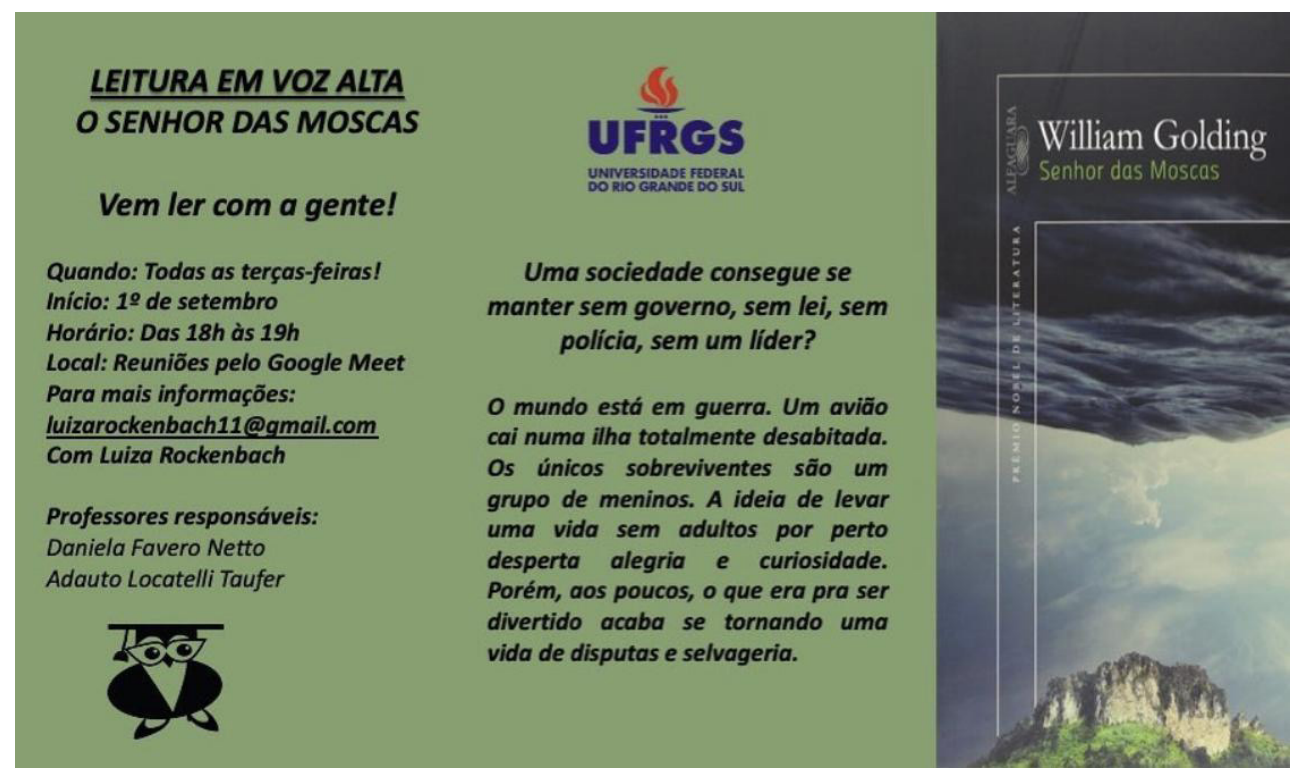

Fonte: Folder elaborado pelos autores.

Os encontros ocorreram todas as terças-feiras, entre setembro e dezembro de 2020, às $18 \mathrm{~h}$, com uma hora de duração, totalizando 15 encontros. O grupo de leitura foi realizado em plataforma on-line, através do Zoom, o que resultou em experiências ainda mais desafiadoras, tendo em vista a novidade de atuação no campo digital para práticas desse tipo, seja para os coordenadores, seja para os mediadores de leitura (bolsistas de pesquisa ${ }^{6}$ ) e para os participantes do grupo.

Para sondar sobre a experiência de leitura dos participantes, inicialmente aplicamos um questionário voltado às experiências de leitura de cada um para entender os hábitos de leitura daqueles jovens. A importância dessa sondagem deve-se ao fato de entendermos que diferentes experiências de leitura certamente acarretariam diferentes estratégias de mediação. Afinal, conforme a antropóloga Michèle Petit, em Os jovens e a leitura - uma nova perspectiva, "o iniciador aos livros é aquele ou aquela que pode legitimar um desejo de ler que não está muito seguro de si. Aquele ou aquela que ajuda a ultrapassar os umbrais em diferentes momentos do percurso" (PETIT, 2009, p. 174). Assim, entender em que medida o participante é um leitor mais ou menos experiente, ou tem mais ou menos contato com livros em sua casa (se seus responsáveis são ou não leitores, por exemplo), ajudou os mediadores a entenderem a diversidade de experiências com leitura de onde partiam os integrantes daquele círculo de leitura que se pretendia constituir. Aqui, denomina-se a proposta como um círculo de leitura na medida em que ele possui

um caráter formativo, proporcionando uma aprendizagem coletiva e colaborativa ao ampliar o horizonte interpretativo da leitura individual por meio do compartilhamento das leituras e do diálogo em torno da obra selecionada - de certa forma, um círculo de leitura tem os mesmos predicados dos Círculos de Cultura de Paulo Freire, que os localizava como espaço de diálogo e participação [...]. (COSSON, 2020, p. 139).

\footnotetext{
60 grupo de pesquisa de que fazem parte os bolsistas chama-se Grupo de Investigação sobre Práticas de Língua Portuguesa e Literatura na Educação Básica. Este grupo busca, a partir da análise de práticas na área de Língua Portuguesa e Literatura promovidas no e pelo Colégio de Aplicação da UFRGS, contribuir com reflexões que possam servir para a construção e a orientação do trabalho de professores no que atine ao ensino e à aprendizagem de leitura, interpretação e produção textual em sala de aula, contemplando os multiletramentos. Trata-se de um tema amplo e, por essa razão, o projeto principal apresenta-se como um macroprojeto, no sentido de que contempla ramificações de projetos menores, todos relacionados à pesquisa sobre ensino em língua portuguesa e literatura. Para o espelho do grupo no CNPq, acessar o link dgp.cnpq.br/dgp/espelhogrupo/6993644198323805.
} 
Ao encerramento da obra, foi aplicado um novo questionário, que trazia perguntas mais direcionadas à experiência daqueles participantes no grupo de leitura em voz alta, para que a devolutiva dos participantes servisse como uma possibilidade de aprimoramento e de revisão das práticas de mediação em propostas futuras.

Os bolsistas de pesquisa (daqui em diante chamados de mediadores), sistematizaram o protocolo de leitura da seguinte forma: realização da leitura da obra na íntegra, ao longo dos 15 encontros, com a possibilidade de interrupção da leitura conforme a necessidade dos participantes de comentar cada trecho lido. Inicialmente não foi fixado um número de páginas para a leitura; porém, com a progressão da leitura, para que todos pudessem participar da experiência de ler a cada encontro, acordamos com o grupo a leitura de duas páginas para cada integrante.

No primeiro encontro, os participantes pareciam muito empolgados com o início das discussões, devido à presença dos dois coordenadores do projeto. Observamos que todos os participantes pareciam muito animados para o início das atividades. Alguns, especificamente, pareciam empolgados em compartilhar até mesmo ideias que se distanciavam bastante do texto lido. Neste primeiro encontro, durante 45 minutos de discussão realizada, somente duas páginas haviam sido lidas. Nesta ocasião, destaca-se a fala de um dos participantes, que comparou Senhor das Moscas à Harry Potter, por conta da presença de crianças e de adolescentes nas narrativas, o que faz muito sentido para a discussão, tendo em vista que também em Senhor das Moscas a narrativa é dominada por personagens que são crianças e adolescentes, com o protagonismo desses personagens no desenvolvimento da trama.

A partir do $2^{\circ}$ encontro, o andamento do grupo ocorreu sob orientação/organização dos mediadores. Dando sequência ao protocolo dos encontros, cabe ressaltar que, primeiramente, realizava-se um breve resumo do que foi lido no encontro anterior, uma recapitulação da leitura e, em seguida, perguntava-se quem que se disponibilizaria a iniciar a leitura do dia. Com o seguimento da leitura (de duas páginas por leitor, como já foi mencionado anteriormente) e o término das discussões após as duas páginas lidas, os mediadores perguntavam quem seria o próximo a ler (a menos, é claro, que alguém se voluntariasse antes). Em termos de comentários e de discussões realizadas a respeito da obra, acordou-se que fossem realizados após o término da leitura de cada participante, ou seja, após duas páginas de leitura. No entanto, isso não se tratava de uma regra que precisava ser seguida de forma fixa: se houvesse algum fato surpreendente acontecendo durante a leitura de um determinado participante e este (ou qualquer outro) quisesse parar para comentar, poderiam fazê-lo. Nos momentos em que não havia nada aparentemente significativo para comentar depois das duas páginas lidas, a leitura seguia.

Um aspecto importante a mencionar aqui foi o fato de poucos participantes se aventurarem a abrir suas câmeras durante os encontros, com exceção do primeiro dia, em que cada um se apresentou ao grupo. Muitas vezes, em alguns encontros, somente as câmeras dos mediadores se encontravam ligadas. Alguns dos participantes, quando indagados no questionário final referente à existência de alguma circunstância que pudesse impedi-los de trazer as suas contribuições e seus pensamentos sobre os assuntos debatidos em grupo, disseram que a vergonha era um dos pontos que os inibia. Parece, portanto, que a vergonha desses jovens, que em sua maioria sequer se conheciam pessoalmente, é um dos fatores por trás das câmeras fechadas. Os problemas com conexão e ou questões pessoais relativas à casa dos participantes também faziam parte da rotina e, em alguns momentos, para eles, parecia inviável estar presente em imagem nesses momentos.

Com o andamento da leitura, os participantes foram se sentindo mais confiantes e, sobretudo, à vontade naquela experiência virtual e, por isso, cada vez mais participantes se disponibilizaram a ler, a comentar e a participar. Além disso, alguns momentos se destacaram, em especial, aqueles em que foi possível perceber as estratégias de mediação de leitura funcionando para o melhor andamento da leitura no grupo. Em um dos momentos da leitura, um dos mediadores resume os acontecimentos do livro para os participantes e finaliza perguntando em relação às ideias que 
os participantes tiveram a partir do primeiro contato entre os dois personagens protagonistas do livro (Ralph e Porquinho). O que foi observado, primeiramente, foi que a partir dessa estratégia de organizar a narrativa, retomando os ocorridos centrais da trama com os participantes, eles se sentiam, de alguma forma, estimulados a participar mais. Isso talvez ocorresse por conta de o processo de organizar e repassar os acontecimentos da narrativa soar para eles como uma construção conjunta, uma espécie de lista colaborativa de tópicos, onde sempre há espaço para mais detalhes, em que eles podem parafrasear a história que acabaram de ler, ou seja, contá-la com suas próprias palavras, ou talvez, ainda, por se sentirem encorajados através das indagações dos mediadores, que pediam suas impressões.

A fim de incentivar os outros a participar, os mais silenciosos, os mediadores passaram a instigá-los com perguntas a respeito da narrativa de Golding: "O que vocês acham que acontecerá com Porquinho e com Ralph?"; "A partir do que lemos aqui, para onde vocês acreditam estar indo a história?”. Dessa forma, tentava-se trazer para a discussão esses participantes mais obstinados ao silêncio (ROUXEL, 2013). Dessa ideia não só surgiram ótimas contribuições, como também se provou uma boa saída para lidar com os silêncios, que são bem-vindos em alguns momentos, mas que precisam ser, por vezes, quebrados. Trata-se, então, de uma estratégia que buscava "infundir-lhes confiança para que ousem pensar a partir de si próprios” (ROUXEL, 2013, p. 22), desfazendo as amarras características especialmente dos estudantes de ensino médio, que tanto temem o erro de interpretação diante de outras pessoas. Como exemplo, há a seguinte situação: o mediador pergunta "O que vocês acham disso?" (referindo-se a um episódio da narrativa), e, em seguida, chama um dos participantes para trazer sua impressão. Conforme a primeira impressão foi manifestada por um dos participantes, outros se sentiram encorajados a revelarem também suas impressões, talvez por perceberem que suas ideias eram validadas ou por perceberem que não chegaram a conclusões errôneas, afinal, as diferentes interpretações não eram tratadas como erradas.

A fim de referendar o que foi exposto, cabe aqui mencionar que, no $8^{\circ}$ encontro especificamente, após um dos mediadores realizar algumas perguntas direcionadas, muitos participantes se sentiram encorajados a trazerem suas ideias. Na ocasião, um dos integrantes comentou da possibilidade de os meninos, reportando-se à narrativa de Golding, estarem sentindo falta de algum adulto dentro da ilha. Ele explica seu raciocínio argumentando que os personagens estão sentindo falta de alguma ordem dentro da ilha, com exemplos de falas. Outro participante comenta que estaria faltando talvez o comprometimento de cada criança com as tarefas, pois não havia ninguém naquela ilha para cobrá-los das obrigações a serem feitas. Com esta fala, outro integrante parece seguir a linha de raciocínio do colega de grupo e argumenta que estaria faltando a presença de uma figura que fiscalizasse e que organizasse as atividades dos meninos. Outro integrante afirma que o que falta para os meninos é que eles sofram com as consequências de sua falta de comprometimento com as atividades da ilha. Os mediadores elogiaram muito os participantes por suas contribuições nesse encontro, afirmando que, além de terem tornado a discussão mais rica, trouxeram questões nas quais nem mesmo eles, os mediadores, haviam pensado. Por isso que, quanto mais novos participantes se aventuravam a comentar e a discutir sobre a narrativa, mais interessante o grupo e as reflexões se tornavam.

As ideias apresentadas pela professora e pesquisadora Cecília Bajour (2012), em Ouvir nas entrelinhas: o valor da escuta nas práticas de leitura, ao refletir sobre o encontro com a palavra do outro por meio de conversas sobre textos, entrelaçam-se à estratégia de mediação aqui relatada. Segundo a autora,

A escuta da interpretação dos outros se entremeia com a nossa. Os fragmentos de sentido que originamos nesse encontro, quando entram em contato com os fragmentos de outros, podem gerar algo novo, algo a que talvez não chegaríamos na leitura solitária. [...] Essa concepção dialógica da escuta faz parte de todo ato de leitura em que se busque abrir significados e expandi-los de modo cooperativo. (BAJOUR, 2012, p. 24-25, grifos nossos). 
Na perspectiva de Bajour, mediadores de leitura, tocados pelo aprendizado da escuta da voz alheia nas discussões e nos debates sobre o compartilhamento das impressões de leitura devem estimular a manifestação da diversidade de possibilidades interpretativas que o texto suscita. $\mathrm{O}$ mediador, então, precisa entender que, além de contemplar essa multiplicidade de vozes, é importante colocar microfones plugados a caixas de som que amplifiquem as vozes de seus leitores, oportunizando que essas vozes reverberem dentro e fora do espaço de discussão de leituras; enfim, que essas vozes ecoem e se propaguem o mais longe possível. Para Bajour, em última análise:

Em experiências de leitura compartilhada, os mediadores que aprendem a ouvir nas entrelinhas constroem pontes e acreditam que as vozes, os gestos e os silêncios dos leitores merecem ser escutados. Se assim for, quando é assim, ler se parece com escutar. (BAJOUR, 2012, p. 45, grifos nossos).

Ainda que o objetivo da mediação seja o de provocar estímulos nos participantes do grupo, a estratégia, por ela mesma, também pode decorrer de um estímulo dado por um participante do grupo; nesse caso, então, a estratégia de mediação seria provocada, antes de planejada. Nesse sentido, um momento que chamou atenção dos mediadores em relação às estratégias de mediação utilizadas que mais contribuíram para a fluidez das conversas no grupo ocorreu no $5^{\circ}$ encontro, foi quando uma participante compartilhou uma ideia nova a respeito de uma situação apresentada na narrativa:

Eu comecei a notar que o Ralph e o Jack começaram a agir como pais das outras crianças. Tipo assim: enquanto o Jack caça, o Ralph tenta fazer o abrigo, ou vice-versa. Eles estão sempre tentando ser responsáveis o suficiente para dar conta de todas as outras crianças e ficam preocupados quando uma delas não está ali.

Em seguida, um dos mediadores acrescentou:

Eu achei muito legal essa tua colocação de que eles estavam fazendo papel de pais. Tanto que teve uma parte do trecho aqui que eu até achei um pouco forte, como "trocaram o olhar contido de amor e ódio". Tipo, como assim de amor e ódio? Pareceu muito coisa de relação familiar, em que amor e raiva convivem em muitas situações.

A partir desse exemplo, fica a pergunta para reflexão futura de pesquisa: quem exerce (ou pode exercer) a função de mediação em um grupo de leitura em voz alta?

A validação do comentário da participante, feita em estratégia de mediação, pareceu ser bastante útil para o andamento das discussões, uma vez que, após esse comentário, a participante foi instigada a dialogar ainda mais e, portanto, propôs-se a contribuir mais vezes com o enriquecimento do grupo a partir das ideias que apareciam. Além disso, o acréscimo à fala da participante, por parte de um mediador, mostra a sua capacidade [do mediador] de, nas palavras de Petit, se deixar "levar por um texto, no lugar de querer [...] controlá-lo." (PETIT, 2013, p. 63). Para os estudantes, não há dúvidas, faz-se importante que os mediadores se permitam também exercitar aquilo que estão propondo: trata-se de um espaço para trocas e construção de conhecimentos, nunca simplesmente de transmissão de conhecimentos. 


\section{Considerações finais}

Para além de dados que foram gerados para análise no âmbito de nossa pesquisa, a atividade de extensão de leitura literária em voz alta voltada a estudantes mostrou-se uma atividade importante, que se encontra em permanente construção, tanto por parte dos mediadores quanto por parte dos participantes. Quer seja por ser uma primeira experiência para ambos os mediadores ou por ser um terreno ainda um tanto quanto incerto sobre o que deixar para ser definido pela dinâmica própria da leitura em grupo e o que definir e estipular previamente, esse primeiro grupo de leitura foi sendo construído na medida em que todos os participantes, bem como mediadores iam entendendo e se adaptando a essa prática. Cabe aqui ressaltar, portanto, que todas as estratégias utilizadas não eram previamente conhecidas pelos mediadores: elas foram sendo percebidas e construídas ao longo da leitura e, desse modo, analisadas e detalhadas posteriormente, ao término do grupo de leitura, para fins de pesquisa.

Todos foram apresentados a uma série de novos desafios advindos do meio on-line: como participantes que não podiam ligar suas câmeras por conta de uma conexão de internet instável, ou aqueles que não poderiam ler em uma semana porque havia uma obra sendo feita em sua casa e, portanto, o barulho não permitiria sua participação, ou até mesmo a internet de um dos mediadores caindo minutos antes da reunião por conta de um problema com o modem.

É claro que os novos tempos se mostraram desafiadores e, algumas vezes, desmotivadores. Houve momentos em que a distância do isolamento tornou a vida apática, de uma forma ou de outra, para todos. E nesses momentos, a distância dessa plataforma on-line tornou-se maior ainda, com câmeras desligadas e poucas participações, mas, assim como antes da pandemia havia desafios na esfera presencial das salas de aula, os quais quase nunca se repetiam, agora também há novos com que lidar.

Ao fim e ao cabo, assim como acontecia antes da COVID-19, os momentos de encontro, de compartilhamento de ideias, de experiências compartilhadas e de conexões que fazemos é que tornam a jornada prazerosa e realizadora; e desses momentos fazem parte também os desafios.

\section{Referências}

BAJOUR, Cecília. Ouvir nas entrelinhas: o valor da escuta nas práticas de leitura. São Paulo: Pulo do Gato, 2012.

COSSON, Rildo. Círculos de leitura e letramento literário. 1. ed. São Paulo: Contexto, 2020.

GOLDING, William. Senhor das moscas. 1. ed. Rio de Janeiro: Objetiva, 2014.

PETIT, Michèle. Os jovens e a leitura: uma nova perspectiva. 2. ed. São Paulo: Editora 34, 2009.

PETIT, Michèle. Leituras: do espaço íntimo ao espaço público. São Paulo: Editora 34, 2013.

ROUXEL, Annie. Aspectos metodológicos do ensino de literatura. In: DALVI, Maria Amélia; REZENDE, Neide Luzia de; JOVER-FALEIROS, Rita (org.). Leitura de literatura na escola. São Paulo: Parábola, 2013. p. 17-33.

Data de submissão: 12/05/2021

Data de aceite: $28 / 06 / 2021$ 